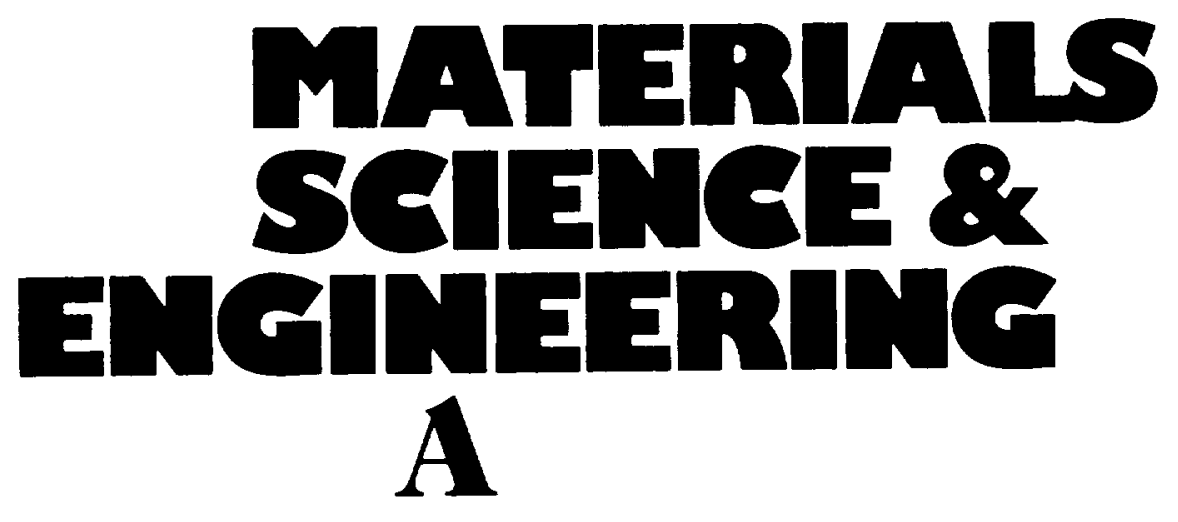

Materials Science and Engineering A208 (1996) 126-130

Cyclic fatigue of brittle materials with an indentation-induced flaw system

Sung R. Choi ${ }^{\mathrm{a},{ }^{*} \text {, Jonathan A. Salem }}{ }^{\mathrm{b}}$

${ }^{a}$ Cleveland State University, Cleveland, OH 44115, USA

${ }^{\circ}$ NASA Lewis Research Center, Cleveland, OH 44135, USA

Received 1 May 1995; in revised form 10 October 1995 


\section{MATERIALS SCIENCE AND ENGINEERING A}

The journal provides an international medium for the publication of theoretical and experimental studies and reviews of the properties and behavior of a wide range of materials, related both to their structure and to their engineering application. The varied topics comprising materials science and engineering are viewed as appropriate for publication: these include, but are not limited to, the properties and structure of crystalline and non-crystalline metals and ceramics, polymers and composite materials.

\section{Editor-in-Chief \\ Professor $\mathrm{H}$. Herman \\ Associate Editors \\ M. Koiwa (Japan) \\ G. Kostorz (Switzerland)}

\section{Editorial Board (MSE A)}

J. Ågren (Sweden)

G. Ananthakrishna (India)

R. J. Arsenault (USA)

D. Brandon (Israel)

H. K. D. H. Bhadeshia (UK)

J. Cadek (Czech Republic)

J. B. Cohen (USA)

J. Driver (France)

J. D Embury (Canada)

$Y$. Estrin (Australia)

H. Fischmeister (Germany)

C. Garcia de Andrés (Spain)

H. Gleiter (Germany)

M. W. Grabski (Poland)

M. Kato (Japan)

Y. G. Kim (Korea)

C. Laird (USA)

J. Lendvai (Hungary)

W. Mader (Germany)

M. McLean (UK)
L. Priester (France)

S. Sampath (USA)

V. K. Sarin (USA)

P. Shen (Taiwan)

$M$. Suery (France)

S. Suresh (USA)

N. S. Stoloff (USA)

M. Taya (USA)

A. K. Vasudévan (USA)

A. Vevecka (Albania)

B. Wilshire (UK)

M. Yamaguchi (Japan)

T. S. Yen (China)

\section{Print and Electronic Media Review Editor} A. H. King (USA)

\section{Administrative Editor}

Barbara Herman

\author{
Advisory Board (MSE A and B) \\ H. Herman, Chairman (USA) \\ $H$. Curien (France) \\ M. E. Fine (USA) \\ A. Kelly, FRS (UK) \\ H. Mughrabi (Germany) \\ H. Rangu (Japan)
}

\section{Types of contributions}

Original research work not already published, plenary lectures and or individual papers given at conferences; reviews of specialized topics within the scope of the journal; engineering studies; letters to the editor

\section{Subscription Information 1996}

Volumes 205-221, each volume containing 2 issues, are scheduled for publication. Prices are available from the publishers upon request. Subscriptions are accepted on a prepaid basis only. Issues are sent by SAL (Surface Air Liftedi mail wherever this service is available. Airmail rates are available upon request. Please address all requests regarding orders and subscription querres to

\section{ELSEVIER SCIENCE SA}

P. O. Box 564, 1001 Lausanne, Switzerland Telephone: (21) 3207381

Telex: 450620 ELSA CH Telefax: (21) 3235444

Issues are sent by surface mail after air delivery to Argentma, Australia, Brazil, Canada, China, Hong Kong, India, Israel, Japan.
Malaysia, Mexico, New Zealand Pakistan, Singapore South Africa, South Korea. Taiwan. Thailand and the USA. Airmail rates for other countries are avallable on request.

For advertising rates apply to the publishers. A specimen copy will be sent on request.

US and Canadian customers may obtain information from the following.

\section{ELSEVIER SCIENCE INC.}

Attn.: Journal Information Center, 655 Avenue of the Americas New York. NY 10010. USA.

Telephone: 121216333750 Telex: 420643 AEP UI

Telefax: (212) 6333764

\section{Abstracting and/or Indexing Services}

American Ceramic Society, Cambridge Scientific Abstracts; Chemical Abstracts; Current Contents; Engineering Index; $\mathrm{FIZ}$ Karlsruhe; Fluid Abstracts; Fluidex; Glass Technology Abstracts; Inspec Physics Abstracts; Metals Abstracts; Pascal (Centre National de la Recherche Scientifique): Physikalische Berichte: Research Alert ${ }^{\mathrm{im}}$. Science Citation Index. 


\title{
Cyclic fatigue of brittle materials with an indentation-induced flaw system
}

\author{
Sung R. Choi ${ }^{\mathrm{a},{ }^{*}}$, Jonathan A. Salem ${ }^{\mathrm{b}}$ \\ "Clevelund State Lniversity, Cletcland, OH 44115, USA \\ ${ }^{\mathrm{h}}$ NASA Lewis Rerearch Conter. Cleveland, OH 44135. USA
}

Received 1 May 1995; in revised form 10 October 1995

\begin{abstract}
The ratio of static to cyclic fatigue life, or ' $h$ ratio', was obtained numerically for an indentation flaw system subjected to sinusoidal loading conditions. Emphasis was placed on developing a simple, quick lifetime prediction tool. The solution for the $h$ ratio was compared with experimental static and cyclic fatigue data obtained from as-indented 96 wt. $\%$ alumina specimens tested in room-temperature distilled water.
\end{abstract}

Keywords: Cyclic fatigue; Static fatigue: Indentation-induced flaw; Ceramics

\section{Introduction}

For glass and ceramic materials which have slow crack growth (stress corrosion) as the unique, time-dependent failure mechanism, it is possible to predict the fatigue life under one loading condition from another. Prediction of cyclic fatigue lifetime from static lifetime for Griffith flaw system can be done analytically by using the ratio of static fatigue to cyclic fatigue life, introduced by Evans and Fuller [1]. In the case of the indentation flaw system, the solution requires a numerical approach since an additional driving force appears in the net stress intensity factor. This term is attributed to residual contact stress produced by the elastic/plastic deformation of indentation [2]. Analyses of dynamic and static fatigue of the indentation flaw system were carried out previously for both postthreshold [3,4] and subthreshold [5] indentation flaws. However, no general solution for the cyclic fatigue of such a flaw system has been found, although some cyclic fatigue data on ceramic specimens containing indentation cracks exist [6-9].

* Corresponding author. Address correspondence to: NASA Senior Resident Research Associate, Lewis Research Center, Cleveland. $\mathrm{OH}$ 44135, USA.
The purpose of this study is to analyze cyclic fatigue of the indentation flaw system under sinusoidal loading conditions so that lifetime prediction from one fatigue condition to another is readily feasible. For this purpose, the complete solution of the ratio of static to cyclic fatigue life was obtained numerically in conjunction with fatigue parameter $(n)$ and stress ratio ( $R$ ratio). The solution was compared with experimental data that were obtained from static and cyclic fatigue testing of indented alumina specimens in room-temperature distilled water. The analysis was carried out for material exhibiting a flat $R$ curve and a power-law crack propagation as a delayed failure mechanism.

\section{Analysis}

In many cases slow crack growth of glass and ceramic materials under Mode I loading conditions is described by the following empirical, power-law relation [4]

$\mathrm{v}=\frac{\mathrm{d} a}{\mathrm{~d} t}=A\left[\frac{K_{1}}{K_{\mathrm{Ic}}}\right]^{n}$

where $t, a$, and $t$ are crack velocity, crack size, and time, respectively. $A$ and $n$ are the fatigue parameters which depend on material and environment. $K_{I}$ is the 

Mode I stress intensity factor, and $K_{\mathrm{IC}}$ is the Mode I critical stress intensity factor or fracture toughness of the material with a flat $R$ curve.

\subsection{Natural flaws}

In static fatigue testing a constant applied stress $(\sigma)$ is employed. Noting that $n \geq 10$ for most glass and ceramics, one can derive the following static fatigue equation [10]

$$
t_{\mathrm{fs}}=B S_{\mathrm{i}}^{n-2} \sigma^{-n}
$$

where $t_{\mathrm{fs}}$ is the time to failure, $S_{\mathrm{i}}$ is the inert strength, and $B$ is the parameter associated with fracture toughness, crack geometry and fatigue parameters.

In cyclic fatigue testing a time-varying, periodic stress $(\sigma(\mathrm{t}))$ is applied. The time to failure $\left(t_{\mathrm{fc}}\right)$ in cyclic fatigue can be expressed as [1]

$$
t_{\mathrm{fc}}=B S_{\mathrm{i}}^{n-2} \sigma_{\max }^{-n} \frac{1}{\frac{1}{\tau} \int_{0}^{\tau}[f(t)]^{n} \mathrm{~d} t}
$$

where $\sigma_{\max }$ is the maximum applied stress, $f(t)$ is a periodic function defined as $\sigma(t)=\sigma_{\mathrm{max}} f(t)$ with a range of $0 \leq f(t) \leq 1$, and $\tau$ is the period. The ratio of static fatigue to cyclic fatigue life, $h$, with a condition of $\sigma$ in static loading equal to $\sigma_{\max }$ in cyclic loading $\left(\sigma=\sigma_{\max }\right)$ can be obtained from Eqs. (2) and (3)

$h=\frac{t_{\mathrm{fs}}}{t_{\mathrm{fc}}}=\frac{1}{\tau} \int_{0}^{\tau}[f(t)]^{n} \mathrm{~d} t$

Sinusoidal loading is the most common and popular wave form used in cyclic fatigue testing. The periodic function $f(t)$ for a sinusoidal wave is expressed as $f(t)=[(1+R) / 2+[(1-R) / 2] \sin \omega t]$, where $R$ is the stress (or load) ratio, defined as $R=\sigma_{\min } / \sigma_{\max }$ with $\sigma_{\min }$ being the minimum applied stress. $\omega$ is the angular velocity. Eq. (4) can be solved either analytically or numerically for the sinusoidal wave. The $h$ ratio for any other periodic loading wave form such as trapezoidal, triangular or square can be solved analytically with a straightforward procedure $[1,11]$. Eq. (4) was solved analytically for a sinusoidal wave by using the series expansion technique of Evans and Fuller [1]. Their analytical solution is expressed as

$h=\sum_{k=0}^{n / 2}\left[\frac{n !}{(n-2 k) !(k !)^{2}}\right]\left[\frac{1-R}{2(1+R)}\right]^{2 k}\left(\frac{1+R}{2}\right)^{n}$

Eq. (5) is still complicated to solve and valid only for integer values of $n$. Therefore, it is desirable to solve Eq. (4) numerically to cover any integer or real value of $n$ for a full range of $R=0-1.0$, even though some limited data on the $h$ ratio exist $[1,12]$.

Fig. 1 shows the results of the numerical solution of Eq. (4) as a function of $n$ for $R$ ratios from $R=0$ to $R=1.0$. If $\log h$ is treated as a linear function of $\log n$, coefficients of correlation of $r_{\text {coef }} \geq 0.9966$ result. Thus it

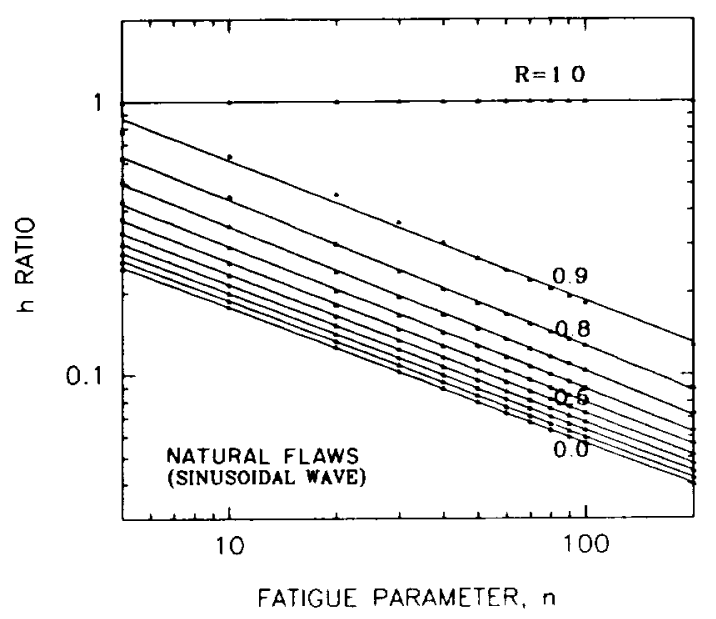

Fig. 1. Numerical solution of the $h$ ratio as a function of fatigue parameter $(n)$ for different levels of $R$ ratios with the natural flaw system. Each line represents a best-fit regression line.

is possible to obtain an approximate (but accurate) relation between $\log h$ and $\log n$ for a given $R$ ratio by using the regression analysis

$\log h=\alpha \log n+\beta$

where $\alpha$ and $\beta$ are the regression coefficients.

Table 1 shows the regression coefficients $\alpha$ and $\beta$. For $n \geq 10$, the maximum error in $h$ ratio, as compared with the exact solution, was $1.0 \%$ for $R=0$ to 0.7 , and $4.5 \%$ for $R=0.8$ to 0.9 . Therefore, the table gives a convenient and accurate means of determining the $h$ ratio for a natural flaw system for any given value of $n$, either integer or real. The complication of a lack of a simple analytical solution to Eq. (5) for real numbers can be eliminated with Eq. (6) and Table 1.

\subsection{Indentation flaws}

Because of the residual contact stress produced by elastic/plastic indentation deformation [2], an addi-

Table 1

Regression coefficients of the $h$ ratio (Eq. (6)) for natural and

\begin{tabular}{|c|c|c|c|c|}
\hline \multirow[b]{2}{*}{$R$} & \multicolumn{2}{|c|}{ Natural flaws } & \multicolumn{2}{|c|}{ Indentation flaws } \\
\hline & $x$ & $\beta$ & $x$ & $\beta$ \\
\hline 0.0 & -0.4939 & -0.2607 & - & 一 \\
\hline 0.1 & -0.4955 & -0.2348 & -0.4856 & -0.1925 \\
\hline 0.2 & -0.4976 & -0.2051 & -0.4885 & -0.1612 \\
\hline 0.3 & -0.5005 & -0.1703 & -0.4925 & -0.1240 \\
\hline 0.4 & -0.5049 & -0.1282 & -0.4977 & -0.0804 \\
\hline 0.5 & -0.5112 & -0.0765 & -0.5049 & -0.0268 \\
\hline 0.6 & -0.5195 & -0.0115 & -0.5126 & -0.0383 \\
\hline 0.7 & -0.5291 & 0.0705 & -0.5198 & 0.1172 \\
\hline 0.8 & -0.5353 & 0.1743 & -0.5173 & 0.2075 \\
\hline 0.9 & -0.5138 & 0.2977 & -0.4743 & 0.2932 \\
\hline 1.0 & 0.0000 & 0.0000 & 0.0000 & 0.0000 \\
\hline
\end{tabular}
indentation flaw systems 
tional term appears in the net stress intensity factor and an analytical solution of cyclic fatigue for the indentation flaw system is not feasible. The solution needs to be done via numerical methods, as done previously for both dynamic and static fatigue analyses involving indentation fracture mechanics $[3,4]$. As in the previous studies $[3,5]$, normalized variables are introduced here as follows:

$K^{*}=\frac{K_{\mathrm{I}}}{K_{\mathrm{IC}}} ; \quad J=\frac{A}{a_{\mathrm{m}}} t ; \quad \sigma^{*}=\frac{\sigma_{\max }}{\sigma_{\mathrm{m}}} ; \quad C^{*}=\frac{a}{a_{\mathrm{m}}}$

where $K^{*}, J, \sigma^{*}$ and $C^{*}$ are, respectively, normalized stress intensity factor, normalized time, normalized maximum applied stress and normalized crack size. $\sigma_{\mathrm{m}}$ and $a_{\mathrm{m}}$ are, respectively, the strength and critical crack size in the inert condition. Using these variables, the crack growth rate of $\mathrm{Eq}$. (1) and net stress intensity factor are expressed as follows:

$$
\begin{aligned}
& \frac{\mathrm{d} C^{*}}{\mathrm{~d} J}=\left[K^{*}\right]^{n} \\
& K^{*}=\frac{3}{4} \sigma_{0}^{*} C^{* 1 / 2}+\frac{1}{4} C^{*-3 / 2} \\
& \sigma_{o}^{*}=\left[\frac{1+R}{2}+\frac{1-R}{2} \sin \left(\frac{\omega a_{\mathrm{m}}}{A}\right) J\right] \sigma^{*}
\end{aligned}
$$

Note that the normalized net stress intensity factor consists of two terms: the first is a function of the remote applied stress and the second is related to the residual contact stress $[2,3]$. The differential form of Eq. (8) was solved numerically using a fourth-order Runge-Kutta method. The initial condition was $C^{*}=$ 0.3967 at $J=0$ and the instability conditions were $K^{*}=1$ and $\mathrm{d} K^{*} / \mathrm{d} C^{*}>0$. The solution was initiated to determine the normalized time to failure $\left(J_{f}\right)$ as a function of normalized maximum applied stress for the selected values of $n=5-160$. This procedure was continued for the range of stress ratios from $R=0.1$ to 1.0 . Since the solution is independent of frequency $(f)$ as long as $\omega a_{\mathrm{m}} / A \geq 2 \pi f$, any particular values of $\omega a_{\mathrm{m}} / A$ satisfying $\omega a_{\mathrm{m}} / A \geq 2 \pi$ can be chosen. A value of $\omega a_{\mathrm{m}} /$ $A=100$ was used in this analysis.

Fig. 2 shows a typical example of the normalized time to failure as a function of normalized maximum applied stress for stress ratios of $R=1.0,0.5$ and 0.1 . Fatigue susceptibility increases with increasing $R$ ratio, yielding a maximum at $R=1.0$ (static fatigue). Note that regardless of $R$ ratio the curves converge to $\sigma^{*}=$ 1.0 , in which the inert strength with no slow crack growth is defined. Similar to the previous static fatigue analysis [4], the slope in Fig. 2 is not representative of a 'true' fatigue parameter of $n$, due to the effect of residual contact stress. The slope in Fig. 2, which is called 'apparent' fatigue parameter $\left(n^{\prime}\right)$, was found to have the following approximate relation

$n=4 / 3 n^{\prime}-2 / 3$

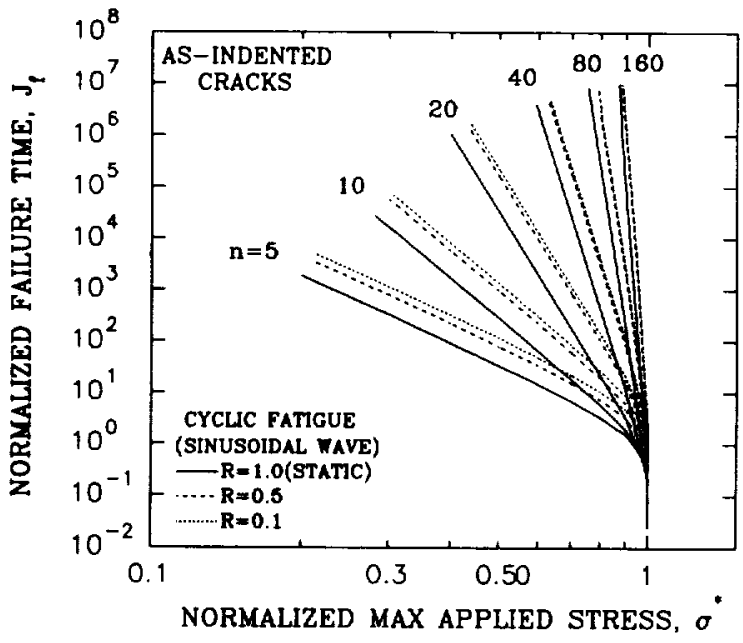

Fig. 2. Typical example of numerically obtained normalized failure time $\left(J_{f}\right)$ as a function of normalized maximum applied stress $\left(\sigma^{*}\right)$ for three different $R$ ratios of $R=0.1,0.5$ and 1.0 for the indentation flaw system.

which reduces to the relationship in static fatigue of indentation cracks [4]. This indicates that the relationship between the true $(n)$ and apparent $\left(n^{\prime}\right)$ fatigue parameters is independent of $R$ ratio.

Based on the results as shown in Fig. 2, the $h$ ratio was determined for a given $R$ using the relation $h=J_{\mathrm{fs}}$ $J_{\mathrm{fc}}\left(=t_{\mathrm{fs}} / t_{\mathrm{fc}}\right)$, where $J_{\mathrm{fs}}$ and $J_{\mathrm{fc}}$ are the normalized time to failure corresponding to static and cyclic fatigue, respectively. Fig. 3 shows a summary of the $h$ ratio as a function of $n$ for $R$ ratios from $R=0.1$ to $R=1.0$, where $\log h$ was plotted against $\log n$ as for the natural flaw system (Fig. 1). Again the excellent coefficients of correlation of $r_{\text {coef }} \geq 0.9911$ allow one to obtain a relationship based on Eq. (6). The results of such regression analysis for $\alpha$ and $\beta$ are shown in Table 1 . The maxi-

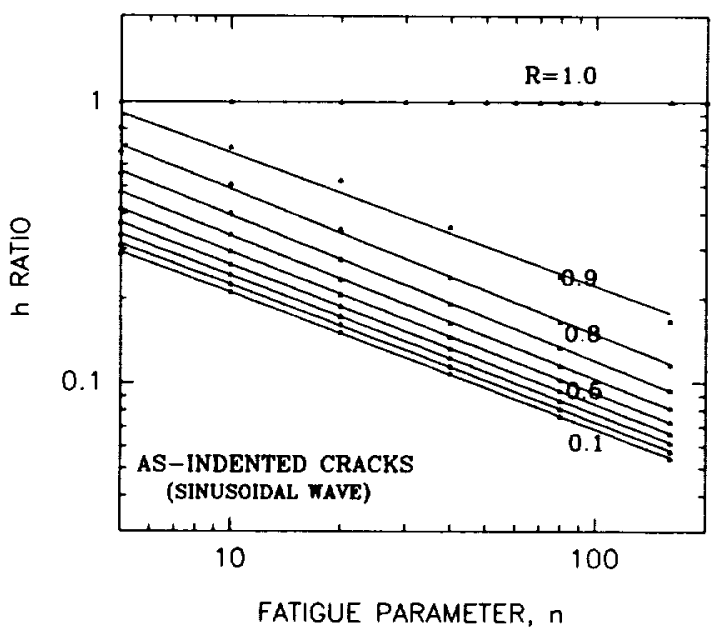

Fig. 3. Numerical solution of the $h$ ratio as a function of fatigue parameter $(n)$ for different $R$ ratios with the indentation flaw system. Each line represents a best-fit regression line 
mum error associated in the $h$ ratio was observed to be about $4 \%$, occurring at $R=0.9$ for $n \geq 10$. Hence, lifetime prediction of an indentation flaw system with one fatigue loading condition can be done quickly and accurately from another by using Eq. (6) in conjunction with Table 1.

\subsection{Evaluation of fatigue parameters for indentation flaws}

The "true" fatigue parameter $n$ for both static and cyclic fatigue can be determined using Eq. (9) once the "apparent" fatigue parameter $n$ ' is determined from the slope of fatigue data. The fatigue parameter $A$ in static fatigue was determined previously [4]

$A=\left(\frac{2 \pi}{n^{\prime}}\right)^{1: 2} \sigma_{\mathrm{m}}^{\prime \prime} \alpha_{\mathrm{m}} \frac{1}{\lambda_{\mathrm{s}}^{\prime}}$

where $i_{s}^{\prime}$ is the intercept of static fatigue data, expressed as $t_{\mathrm{s}} \sigma^{\prime \prime}=\lambda_{\mathrm{s}}^{\prime}$. Since the following relation for the indentation flaw system holds

$\frac{J_{\mathrm{ls}}}{J_{\mathrm{fc}}}=\frac{t_{\mathrm{fs}}}{t_{\mathrm{fc}}}=\frac{\lambda_{\mathrm{s}}^{\prime} \sigma^{-\prime \prime}}{\lambda_{\mathrm{c}}^{\prime} \sigma_{\max }^{\prime \prime}}=\frac{\lambda_{\mathrm{s}}^{\prime}}{\lambda_{\mathrm{c}}^{\prime}}=n$

where $\lambda_{c}^{\prime}$ is the intercept of cyclic fatigue data as $t_{\mathrm{fc}} \sigma_{\text {max }}^{n^{\prime}}=\lambda_{\mathrm{c}}^{\prime}$. Hence, from Eqs. (10) and (11), the parameter $A$ in cyclic fatigue is obtained

$A=\left(\frac{2 \pi}{n^{\prime}}\right)^{1 / 2} \sigma_{\mathrm{m}}^{\prime \prime} a_{\mathrm{m}} \frac{1}{\lambda_{\mathrm{c}}^{\prime} h}$

\section{Experimental procedure}

Static and cyclic fatigue tests of indented alumina $(96$ wt. $\%$, ALSIMAG 614, General Electrical Ceramics) flexure specimens were carried out in room-temperature distilled water using a four-point bend fixture of $6.05 \mathrm{~mm}$ inner and $19.05 \mathrm{~mm}$ outer spans. The nominal dimensions of the test specimens were $4 \mathrm{~mm}$ by $5 \mathrm{~mm}$ by 25 $\mathrm{mm}$, respectively, in height, width, and length. The center ( $5 \mathrm{~mm}$ side) of each specimen was indented in air for about $20 \mathrm{~s}$ using a Vickers microhardness indenter (Zwick, model 3212, Germany) with an indentation load of 49 N. Static fatigue testing was conducted by loading indented specimens in a lever-arm creep machine (ATS) with constant stress levels of 95 to $133 \mathrm{MPa}$. Cyclic fatigue testing of indented specimens was conducted by sinusoidal loading with a stress ratio of $R=0.5$ and a frequency of $f=5 \mathrm{~Hz}$ with a servohydraulic testing machine (Instron, Model 8562). The maximum applied stress in cyclic fatigue ranged from 100 to $130 \mathrm{MPa}$. The sinusoidal wave shape was frequently checked and verified by a digital storage oscilloscope.

\section{Results and discussion}

The results of the static and cyclic fatigue testing of the indented $96 \mathrm{wt} \%$ alumina specimens in room-tem-

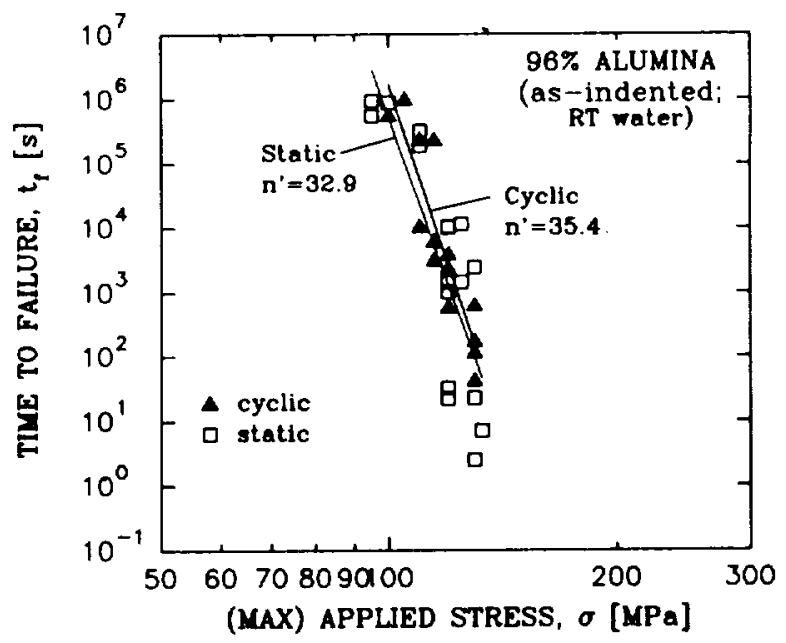

Fig. 4. Results of static and cyclic fatigue testing obtained from indented $96 \mathrm{wt} .1 \%$ alumina flexure specimens tested in room-temperature distilled water. The solid lines represent the best-fit lines in a plot of $\log t_{\mathrm{f}} \mathrm{vs} . \log \sigma_{\max }$

perature distilled water are depicted in Fig. 4. Consistent with the results shown in Fig. 3, the alumina is slightly more susceptible to fatigue in static loading than in cyclic loading within the experimental range used. The "apparent" fatigue parameter was obtained from the data as $n^{\prime}=32.92 \pm 6.01$ and $35.37 \pm 4.79$, respectively, for static and cyclic fatigue. The corresponding "true" fatigue parameter was obtained from Eq. (9) as $n=43.23 \pm 8.01$ and $46.49 \pm 6.39$, respectively, for static and cyclic fatigue. The prediction of cyclic fatigue from static fatigue data can be done using Eq. (6) together with Table 1. The prediction thus made is presented in Fig. 5, where the cyclic fatigue data obtained from the experiments are included for comparison. The prediction somewhat overestimates (less

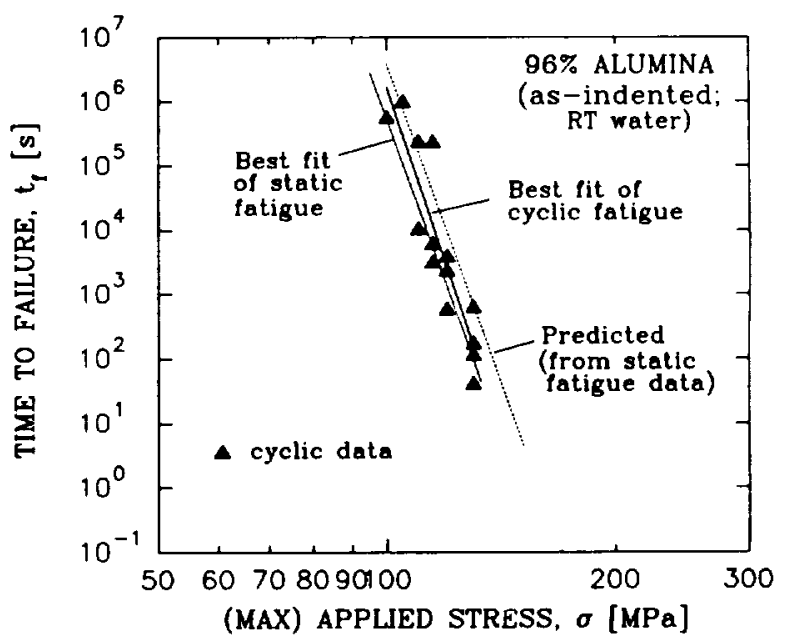

Fig. 5. Prediction of cyclic fatigue lifetime from static fatigue data for indented $96 \mathrm{wt} \%$ alumina specimens tested in room-temperature distilled water. 
than one order of magnitude) the actual cyclic time to failure.

It has been reported that, for certain ceramic materials, damage accumulation and/or fatigue synergisms can be active in cyclic fatigue, resulting in more fatigue susceptibility in cyclic than in static loading $[8,13-16]$. If such synergies exist or if creep at elevated temperatures is simultaneous with cyclic fatigue, the analysis given in this paper may not be valid. However, the analysis may still provide, by comparing with experimental data and by using fractographic analysis, some clues with which the prevailing mechanism associated with failure can be pinpointed. It should be noted that most of glass and ceramic materials under static fatigue loading conditions in a room-temperature moisture environment are subjected to one failure mechanism, stress corrosion. Therefore, in view of the reasonable agreement between the static and cyclic fatigue data shown here, it can be stated that stress corrosion is a governing failure mechanism, either in static or in cyclic loading conditions. This is supported by the fact that the material contains a large amount of glassy phase, which is highly susceptible to stress corrosion in an aqueous environment. The fatigue parameters for this material system, therefore, can be obtained by using either static or cyclic fatigue testing. In terms of testing economy, however, static fatigue is preferred because of the much higher testing costs associated with cyclic fatigue testing.

As mentioned before, the analytical solution of the $h$ ratio for other loading functions such as trapezoidal, triangular and square wave forms can be easily obtained for the natural flaw system because of their mathematical simplicity $[1,11]$. However, the conventional numerical solution for these loading functions may not be simple for the indentation flaw system, since the functions, unlike the sinusoidal wave, are not continuous but discontinuous in nature. In this case, each discontinuous periodic function should be converted into a continuous periodic function so that numerical solution is feasible. This may be done by using the Fourier analysis from which a discontinuous function can be approximated into a continuous function.

\section{Conclusions}

The ratio of static to cyclic fatigue life, or $h$ ratio, was obtained numerically with an emphasis on the indentation flaw system subjected to sinusoidal loading conditions. The $h$ ratio decreases with increasing $n$ and decreasing $R$ ratio. The solution provides a simple and quick methodology to predict the lifetime of one fatigue condition from another for indentation flaw systems (as well as the natural flaw system) when the governing failure mechanism is stress corrosion. The solution was compared with static and cyclic fatigue data obtained from indented $96 \mathrm{wt} \%$ alumina specimens tested in room-temperature distilled water.

\section{Acknowledgements}

The authors are grateful to R. Pawlik for the experimental work. This work was sponsored in part by the Ceramic Technology Project, DOE Office of Transportation Technologies, under contract DE-AC05$840 R 21400$ with Martin Marietta Energy System, Inc.

\section{References}

[1] A.G. Evans and E.R. Fuller, Crack propagation in ceramic materials under cyclic loading conditions, Metall. Trans., 5 (1974) 27-33.

[2] B.R. Lawn, A.G. Evans and D.B. Marshall, Elastic/plastic indentation damage in ceramics: the median/radial crack system, $J$. Am. Ceram. Soc., 63 (1980) 574-581.

[3] B.R. Lawn, D.B. Marshall, G.R. Anstis and T.P. Dabbs, Fatigue analysis of brittle materials using indentation flaws, Part 1 General theory, J. Mater. Sci., 16 (1981) 2846- 2854.

[4] E.R. Fuller, B.R. Lawn and R.F. Cook, Theory of fatigue for brittle flaws originating from residual stress concentrations, $J$. Am. Ceram. Soc., 66 (1983) 314-321.

[5] S.R. Choi, J.E. Ritter and K. Jakus, Failure of glass with subthreshold flaws, J. Am. Ceram. Soc., 73 (1990) 268-274

[6] C.-K.J. Lin and D.F. Socie, Static and cyclic fatigue of alumina at high temperatures, J. Am. Ceram. Soc., 74 (1991) 1511-1518.

[7] S. Lathabai, Y.-W. Mai and B.R. Lawn, Cyclic fatigue behavior of an alumina ceramic with crack-resistance characteristics, $J$. Am. Ceram. Soc., 72 (1989) 1760-1763.

[8] S. Horibe and R. Hirahara, Cyclic fatigue of ceramic materials: influence of crack path and fatigue mechanisms, Acta Metall. Mater., 39 (1991) 1309-1317.

[9] R.H. Dauskardt, R.R. James, J.R. Porter and R.O. Ritchie, Cyclic fatigue-crack growth in $\mathrm{SiC}$ whisker-reinforced alumina ceramic composite: long- and small-crack behavior, J. Am. Ceram. Soc., 75 (1992) 759-771.

[10] (a) J.E. Ritter, P.B. Oates, E.R. Fuller and S.M. Wiederhorn, Proof testing of ceramics, Part 1 Experiment, J. Mater. Sci., 15 (1980) 2275-2281. (b) E.R. Fuller, S.M. Wiederhorn, J.E. Ritter and P.B. Oates, Proof testing of ceramics, Part 2 Theory, $J$ Mater. Sci., 15 (1980) 2282-2295.

[11] J.A. Salem and S.R. Choi, Bimonthly Progress Report, April/ May 1994, Ceramic Technology Project, Oak Ridge National Laboratory, Oak Ridge, TN.

[12] T. Kawakubo and K. Komeya, Static and cyclic fatigue behavior of a sintered silicon nitride at room temperature, Metall. Trans., 70 (1987) $400-405$.

[13] D.A. Krohn and D.P. H. Hasselman, Static and cyclic fatigue behavior of a polycrystalline alumina, J. Am. Ceram. Soc., 55 (1972) 208-211.

[14] L. Ewart and S. Suresh, Crack propagation in ceramics under cyclic loads, J. Mater. Sci. Lett., 22 (1987) 1173-1192.

[15] M.J. Reece, F. Guiu and M.F. R. Sammur, Cyclic fatigue crack propagation in alumina under direct tension-compression loading, J. Am. Ceram. Soc., 72 (1989) 348-352.

[16] R.H. Dauskardt, D.B. Marshall and R.O. Ritchie, Cyclic fatigue-crack propagation in magnesia-partially-stabilized zirconia ceramics, J. Am. Ceram. Soc., 73 (1990) 893-903. 


\section{Instructions for Authors}

\section{SUBMISSION OF PAPERS}

Manuscripts for the main part of the journal and for the Letters Section should be submitted as follows

For authors in Europe

Editor-in-Chief

Professor Herbert Herman

Department of Materials Science and Engineering

State University of New York at Stony Brook

Long Island. NY 11794-2275, USA

Fax: +1 (516) 6328052

or

Professor Gernot Kostorz

ETH Zurich

Institut für Angewandte Physik

CH-8093 Zurich. Switzerland

Fax: +41 (1633) 1105

For authors in Japan

Professor Masahiro Koiwa

Department of Metal Science and Technology

Faculty of Engineering

Kyoto University

Yoshida-Honmachi, Sakyo-ku

Fax: +81 (75) 7517844 world

Professor Herbert Herman

USA

\section{Manuscripts}

Three copies should be submitted to the Editor, in double-spaced typing on pages of A4 size and with wide margins (Letters

should not exceed 2000 words and a maximum of 5 figuresi. All tables and illustrations should bear a title or legend

An abstract should accompany reviews, onginal papers and Letters. It should present (preferably in 100-150 words; 50 words or less for Lettersl a brief and factual account of the contents and conclusions of the paper, and an indication of the relevance

References should be indicated by numerals in square brackets introduced conseculively and appropriately in the text.
Kyoto 606-01, Japan

For authors in North and South America and the rest of the of new material.

References must be fisted on separate sheetisl at the end of the paper. Every reference appearing in the text should be quoted in the reference list, and vice versa. When reference is made to a publication written by more than two authors it is preferable 10 give only the first author's name in the text followed by "et al." However, in the list of references the names and initials of all authors must be given.

Three sets of figures should be submitted. One set of line drawings should be in a form suitable for reproduction, drawn in Indian ink on drawing or tracing paper (letter height, $3-5 \mathrm{~mm}$ ) Alternatively, such illustrations may be supplied as high contrast. black-and-white glossy prints. Duplicate original micrographs should be provided wherever possible to faclitate the refereeing process. Magnifications should be indicated by a ruled scale bar on the micrograph. Captions to llustrations should be typed in sequence on a separate page.

All abbreviated terms must be defined when lirst used (both in the abstract and in the text) and authors must express all quantities in SI units, with other units in parentheses if desired. Authors in Japan please note that information about how to have the English of your paper checked, corrected and improved (before submission) is avarlable from: Elsevier Sclence (Japan). 20-12 Yushima 3-chome, Bunkyo-ku. Tokvo 113; Tel 1031 38333821; Fax: (03) 3836-3064.

\section{Further information}

All questions arising after the acceptance of manuscripts, especially those relating to proofs. Should be directed to Elsevier Editorial Services Mayfield House 256 Banbury Road Oxford OX2 7DH. UK (tel +44 1865 314900: fax +44 1865 314990)

\section{Submission of electronic text}

The final text may be submitted on a 3.5 in or 5.25 in diskette lin addition to a hard copy with original figures). Double density (DD) or high density (HD) diskettes are acceptable, but must be formatted to their capacity before the files are copied on to them. The main text, list of references, tables and figure legends should be stored in separate text files with clearly identifiable file names. The format of these files depends on the word processor used. WordPerfect 5.1 is the most preferable but for other formats please refer to the Instructions to Authors booklet. It is essential that the name and version of the wordprocessing program, type of computer on which the text was prepared, and format of the text files are clearly indicated.

The final manuscript may contain last minute corrections which are not included in the electronic text but such corrections must be clearly marked on the hard copy.

$0921-5093.96 \$ 15.00$ (C) 1996-Elsevier Science. All rights reserved No part of this publication may be reproduced. stored in a retrieval system or transmitted in any form or by any means, electronic mechanical, photocopying, recording or otherwise, without the prior written permission of the publisher, Elsevier Science SA, PO Box 564 1001 Lausanne. Switzerland.

Submission of an article for publication implies the transfer of the copyright from the author(s) to the publisher and entails the author(s) irrevocable and exclusive authorization of the publisher to collect any sums or considerations for copying or reproduction payable by third parties.

Upon acceptance of an article by the journal, the author(s) will be asked to transter copyright of the article to the publisher. This transter will ensure the widest possible dissemination of information

\section{For Material Subject to US Copyright Law}

Special regutations for readers in the USA

This journal has been registered with the Copyright Clearance Center, Inc Consent is given for copying of articles for personal or internal use. or for the personal use of specific clients. This consent is given on the condition that the copler pavs through the Center the per-copy fee stated in the code on the first page of each articte for copying beyond that permited by Sections 107 ar 108 of the US Copyright Law. The appropriate fee should be forwarded with a copy of the first page of the article to the Copyright Clearance Center, Inc. 222 Fosewood Drive, approprate tee should be forwarded a d n code apoars in an article, the author has not given broad consent to copy and permission to copy must be obtained drectly from the author The fee indicated on the first page of an article in this issue will apply retroactively to all articles published in the ournal regardless of the year of publication This consent does not extend to other kinds of copying, such as for general distribution. resaie advertising and promotion purposes or for creating new collective works. Specia written permission must be obtaned from the publisher for such copying.

No responsibility is assumed by the Publisher for any injury and or damage 10 persons or property as a matter of products liabelity. negigence or otherwise of from any use or operation of any me:hods, products, instructions or ideas contained in the material herein.

The paper used in this publication meets the requrements of ANSI NISO $23948-1992$ iPermanence of Paperi.

Printed in The Netherlands 
